Gerda Henkel Vorlesung 
Gerda Henkel Vorlesung

herausgegeben von der gemeinsamen Kommission

der Rheinisch-Westfälischen Akademie der Wissenschaften und der Gerda Henkel Stiftung 


\title{
Denkmäler eines hethitischen Großkönigs des 13. Jahrhunderts vor Christus
}

\author{
Kurt Bittel
}

Springer Fachmedien Wiesbaden GmbH 
Der Vortrag wurde am 29. März 1984 in Düsseldorf gehalten.

CIP-Kurztitelaufnahme der Deutschen Bibliothek

Bittel, Kurt:

Denkmäler eines hethitischen Großkönigs des 13. Jahrhunderts vor Christus: [d.Vortrag wurde am 29. März 1984 in Düsseldorf gehalten]/Kurt Bittel. - Opladen: Westdeutscher Verlag, 1984.

(Gerda Henkel Vorlesung)

ISBN 978-3-322-98851-5 ISBN 978-3-322-98850-8 (eBook)

DOI 10.1007/978-3-322-98850-8

(C) 1984 by Springer Fachmedien Wiesbaden

Ursprünglich erschienen bei Westdeutscher Verlag GmbH, Opladen 1984. 


\section{Vorwort}

Es ist für die Gerda Henkel Stiftung eine besondere Freude gewesen, daß sie Herrn Bittel für eine Gerda Henkel Vorlesung über ein zentrales Thema seiner Forschungen gewinnen konnte. Gehört er doch zu den Archäologen, die nicht nur bedeutende Einzelfunde gemacht haben; es ist ihm gelungen, einen entscheidenden Beitrag zur Entdeckung einer ganzen Kultur zu leisten, der Kultur der Hethiter.

Über Jahrhunderte war von diesem Volk im Grunde nur sein Name bekannt, der im alten Testament erwähnt wird. Noch vor 100 Jahren wußte man kaum näheres von diesem Volk und seiner Kultur. Heute steht die Geschichte dieses Staates im 2. Jahrtausend v. Chr. in ihren wesentlichen Zügen deutlich vor uns. Wir sehen das Hethiterreich als einen der Staaten, die in jener Epoche zusammen mit Ägypten und Babylon ein „Konzert der Großmächte“ bildeten, aus deren Beziehungen auch die ersten Anfänge eines Völkerrechts sich herausbilden konnten. Erst damit ist unser Bild vom alten Orient vollständig geworden.

Herr Bittel hat einen entscheidenden Anteil an dieser Erweiterung unseres geschichtlichen Wissens. Der hier veröffentlichte Vortrag zeigt diese Fortschritte in exemplarischer Weise. 1834 wurde die Statue des hethitischen Herrschers, von dem sein Vortrag handelt, noch als geheimnisvolle Statue eines Sultans gezeigt. Der Vortrag kann nun das Bild eines individuellen hethitischen Herrschers, einer bestimmten historischen Figur, entwickeln - eines bedeutenden und eines baufreudigen Regenten, der zwischen 1250 und 1220 v. Chr. regiert hat.

Der Vortrag zeigt dem Leser damit die bewundernswerten Leistungen, welche die Disziplin, der Kurt Bittel sein Leben gewidmet hat, vollbringen konnte.

\section{Helmut Coing}

